\title{
By The Numbers: Individual Bias and Enterprise Risk Management
}

\author{
Jennifer Blaskovich \\ University of Nebraska - Omaha \\ Eileen Z. Taylor \\ North Carolina State University
}

\begin{abstract}
In theory, enterprise risk management (ERM) appears to be a succinct and effective risk management model. In practice, as is the case with most managerial techniques, the devil is in the implementation. This study explores this issue by examining how the composition of ERM groups determines which risks are managed and which risks are ignored. In two experiments, we find that groups with accounting or financial backgrounds place greater emphasis on financial risks compared with cross-functional groups. Results suggest that organizations will achieve different ERM outcomes from using cross-functional groups than financially oriented group.
\end{abstract}

\section{Introduction}

In 2007, David Martin and Michael Power announced the "end of Enterprise Risk Management" (ERM). The two noted critics of ERM suggested that the practice is a "poor descriptive and normative model" that has less to do with managing risk and more to do with serving the professional interests of accountants and regulators $(2007,9)$. They called for a critical transformation in our approach to risk and predicted the death of ERM as we know it. To the delight of ERM proponents, their message appears to have fallen on deaf ears. A recently conducted survey indicates "unprecedented levels of interest" in ERM by top management and in boardrooms (Mehta, 2010,68). With our apologies to Martin and Power, ERM's passing appears greatly exaggerated, or at the very least, largely ignored.

ERM first entered the business lexicon two decades ago, and has since developed into the gold standard of corporate governance practices. It has been termed a "new paradigm" for risk management - one that proponents claim can break down organizational silos, create and enhance value, and reduce earnings volatility (Barton, Shenkir, \& Walker, 2002). This approach to risk management focuses on identifying, assessing and managing the holistic portfolio of risks facing the entire organization. ERM's popularity skyrocketed in the aftermath of the financial reporting scandals of the early 2000s, as stakeholders demanded greater oversight of risks. Regulatory reforms such as Sarbanes-Oxley also increased the spotlight on corporate governance and raised the stakes on board responsibility for risk management (Beasely, Clune, \& 
Hermanson, 2005). In addition, in 2004, the Committee of Sponsoring Organizations of the Treadway Commission (COSO) issued Enterprise Risk Management - Integrated Framework, which has become a worldwide template for ERM (Power, 2009).

With stakeholders, regulators, and influential accounting and finance groups demanding strong and active ERM, we should expect that Enron-style disasters will remain firmly in our rearview mirror. ERM is, after all, designed to create a culture of risk awareness through a structured and disciplined approach to risk management across the entire organization (Barton, Shenkir, \& Walker, 2002). Of course, the proverbial elephant in the ERM room is the near-catastrophic financial system meltdown in 2008. If ERM is the solution to unmitigated risk, it is shocking to note that some of the most financiallyliterate executives at venerable Wall Street institutions made some of the "most egregious risk miscalculations in history" (Barton, Shenkir, \& Walker, 2010, p. 20). Ironic, considering that the banking and financial industry had been labeled a leader in ERM and risk oversight (Protiviti, 2010). Further, federal regulators charged with industry oversight appear to have ignored lessons learned from the savings \& loan crisis of the 1980s and 1990s. Their complicity in this most recent debacle proves that risk mismanagement is not exclusive to the private sector. Lest we assume that this was less a failure of ERM and more the result of ignorance of highly complex derivatives, we need only look to Toyota and British Petroleum for clear examples of seemingly obvious risks that simply were not 'managed'. Where then, was ERM? Were Power and Martin right?

In this paper, we explore this issue by examining how seemingly reasonable choices in implementation can wholly affect the outcome of the ERM process. Specifically, we examine how the choices of individuals involved in the prioritization of risks determine which risks are managed and which risks are ignored. As the name implies, ERM is an enterprise-wide approach to risk management. Champions of ERM stress that organizations must draw upon the knowledge and skills of individuals from across the company in order to execute a truly comprehensive risk management practice (Barton, Shenkir, \& Walker, 2002; Fraser \& Simkins 2007). Reports from practice indicate however, that organizations rely heavily on the accounting function (Fraser \& Simkins 2007; Mikes, 2009; Power, 2009; Walker, Shenkir, \& Barton 2003). This is particularly likely in the risk prioritization activity. Although firms generally engage cross-functional teams to generate initial risk lists (risk identification), they often use homogeneous groups of financially trained employees to narrow that list to a final risk inventory (prioritization). Therefore, while an initial list may represent varied views, the group responsible for prioritization determines the final risk list. The primary research question we explore is whether and how a singular reliance on accounting or financially oriented personnel in prioritization affects the outcome of an ERM process.

In our first experiment, we find that homogenous groups composed of individuals with an accounting background place greater emphasis on financial-related risks than do cross-functional teams composed of individuals with varying backgrounds. Specifically, homogeneous accounting groups include more financial-related risks in a final risk 
inventory and rank them higher on those lists. These groups also rate the financialrelated risks as having greater significance to the organization than other, non-financial risks. This singular focus could prevent managers from recognizing and addressing non-financial risks of significant importance.

In a second experiment, we explore whether this financial focus is specific to accountants or if it extends to others with financial backgrounds. Some research on the balanced scorecard (e.g., Ittner, Larcker, \& Meyer 2003) suggests that a focus on financial indicators may not be exclusive to accountants. Accordingly, our second experiment groups individuals who have a financial, but non-accounting background to complete the same risk tasks. We find that financial focus is not specific to accountants, and that other groups whose members are financially oriented place greater emphasis on financial-related risks than do cross-functional groups. Our second experiment's findings provide further support for the argument that group composition significantly affects the outcome of risk prioritization in the ERM process.

In summary, results from two experiments suggest that organizations will achieve different outcomes from cross-functional groups than from financially oriented groups. We do not make assumptions in our study that one outcome is superior to the other, but rather argue that organizations should be aware that group composition may influence the outcome. Nor do we suggest that the financial risks may not, in fact, be worthy of greater emphasis. But, if we assume that some non-financial risks may be as important as financial risks, then the findings support the suggestions of ERM consultants and researchers (e.g., Fraser \& Simkins, 2007; Shaw, 2005) who call for representative, mixed groups throughout ERM implementation. Our primary objective is to explore how group composition affects a purportedly enterprise-wide initiative. Organizations whose current process relies on homogenous groups of individuals with accounting or financial backgrounds should be aware of bias toward financial risks and might consider the choice of personnel involved in the ERM process with this bias in mind.

\section{Background and Hypotheses}

Beasley and Frigo (2007) argue that as the volume and complexities of risks affecting an organization continuously increase, expectations for effective risk management are at an all-time high. In response, ERM has emerged as the new paradigm of risk management (Beasely, Clune, \& Hermanson, 2005). Although risk management is not a new concept, ERM is a significant departure from traditional practices when organizations tended to identify and manage risks inconsistently, if at all. Traditional risk management was mainly the concern of accounting, finance, compliance, or internal audit managers, with a focus on the quantitative analysis of financial and insurable risks (Barton, Shenkir, \& Walker, 2002; Beasley \& Frigo, 2007; Calandro \& Lane, 2006; Shenkir \& Walker, 2006). Even though organizations may mitigate these types of risks appropriately, such strategies may unintentionally increase risks for other areas of the business. Resources available to mitigate risk may be misallocated, exposing organizations to enormous risks in one area of the business while relatively minor risks in others are excessively managed (Barton, Shenkir, \& Walker, 2002). The goal of ERM 
is the establishment of an integrated program to identify and consider the interactive effects of risk on the organization as a whole (Beasley \& Frigo, 2007).

ERM is a relatively straightforward and simple model: risk identification, risk prioritization, and strategic planning (Power, 2009). Because the broad scope of ERM requires input from across the organization, upper management often calls upon managers from various functional areas to identify their function's risks. Next, a designated management group prioritizes the identified risks. Finally, senior executives, the board of directors, and the audit committee review and manage the top-priority risks (Barton, Shenkir, \& Walker, 2001; Shaw, 2005). A critical implementation issue that arises when executing the prioritization task is the determination of the composition of the risk management group. Reports from practice indicate a strong reliance on accounting and financially oriented personnel for ERM tasks and responsibility (Fraser \& Simkins 2007; Mikes, 2009; Power, 2009; Walker, Shenkir, \& Barton, 2003). A recent survey of ERM in practice found that the majority of ERM functions are housed in accounting-related units, including internal audit, controllership, Office of the CFO, and Treasury (Mehta, 2010). Accounting officers are often responsible for risk management efforts (Beasely, Banson, \& Hancock, 2008). This reality can be traced to the historical monopoly over risk granted to the accounting profession (Power, 2004), the strong relationship between ERM and accounting conceptions of internal control (Power, 2009), the increasing influence of the COSO (2004) ERM framework (Mehta, 2010), and the pressures of compliance with Sarbanes-Oxley requirements (Barton, Shenkir, \& Walker, 2010).

While the accounting function may seem a logical place for ERM responsibilities, reliance on one type of organizational expertise will inevitably result in risk management practices skewed toward that area (Fraser \& Simkins, 2007; Shaw, 2005). This problem is not exclusive to the current state of ERM and accounting, having been debated decades ago by those involved in health and safety regulations. At that time, appropriate risk analysis and prioritization was mired in the conflict between science and values (Mayo \& Hollander, 1991). The primary argument stemmed from the belief that all risks are identified and framed by those performing the risk management task (March \& Shapira, 1987). Risk decisions, therefore, are subject to framing and personal biases, as well as the culture of an organizational unit (Mikes, 2009).

Closely related is the current ERM concept of risk appetite, which drives the analysis and prioritization of risks. Risk appetite is the "amount of risk that an organization is willing to tolerate in pursuit of its objectives" (Mehta, 2010, p. 31). A problem arises because an organization cannot determine this benchmark. Rather, individual actors within the organization determine the tolerance for risk. Risk appetite is therefore inevitably comprised of the values, attitudes, and situational experiences of these actors, which may change over time (Power 2009). It is closely tied to corporate culture and managerial focus. Managers, for example, who tend toward quantitative management techniques, will produce different measures of tolerance than those adhering to qualitative methods (Mehta, 2010). Further, recent research indicates that we cannot assume that the attitudes and tolerances of the board or senior management 
are effectively communicated to those completing the risk prioritization process (Protiviti, 2010). In sum, the focus of those responsible for the analysis will affect which risks are managed and which risks are not. We are left with no clear answer to the question Power (2009, p. 851) asks: "whose appetite counts?"

Once this risk prioritization is completed, the analysis is directed to senior management, the board of directors and the audit committee. Accordingly, the framing and potential biases of those in charge of the analysis have necessarily determined the risk landscape known to those in charge of the subsequent strategic planning. It is not feasible to simply present all identified risks to the board, allowing them to analyze and prioritize. Surveys of practice indicate that the time allocated to ERM discussion at each board meeting is between 30-60 minutes. Furthermore, the analysis group typically reports the top ten risks, according to their determination of what risks merit Board level discussion (Mehta, 2010). This implies that the top ten risk list absolutely determines what the board knows. Accordingly, identification of framing or personal focus in the risk prioritization activity is a critical issue because it affects the information set available to the primary corporate governance function of the organization. If accounting professionals are heavily involved in risk prioritization, does their financial focus dictate the outcome?

Prior research in managerial accounting supports the notion that accounting professionals exhibit tendencies to focus on financial information. Mendoza and Bescos (2001) surveyed top-level executives and reported a common complaint: information needed for strategic decision-making and provided by accounting professionals is too heavily skewed toward financial issues and indicators. The managers were forced to develop their own search strategies to overcome this bias. Melone (1994) found that generalist managers exhibited a balanced view of various strategic and financial attributes of a problem while accounting managers placed predominant weight on financial matters.

This is particularly concerning because one clear trait of successful ERM programs is the organization's commitment to tapping the expertise and knowledge from various functional areas (Barton, Shenkir, \& Walker, 2002; Fraser \& Simkins, 2007). ERM requires a wide range of skills, from financial to operational to technical, which no single specialty or business unit possesses. The simplest way to accomplish this is to assemble a cross-functional team representing various areas of the business for risk management tasks. Teams comprised of members with various backgrounds and skills have access to more diverse knowledge and information, enabling the team to develop superior solutions that integrate and address a wider range of issues and strategies (Hoffman \& Maier, 1961). Diversity in groups increases the cognitive resources, problem-solving ability, and breadth of perspective (Hambrick, Cho, \& Chen 1996; Hoffmann \& Maier, 1961). In the case of ERM, a cross-functional group should allow the development of an integrated approach that addresses and evaluates risks facing the entire organization. In contrast, a homogenous group of accountants will be more likely to focus on financially related risks. The instruction and experience gained in the financially-focused discipline of accounting are expected to be retrieved in the judgment 
and decision-making process (Birnberg \& Shields, 1984). We examine this argument as it pertains to analysis and prioritization of risks. We contend that a financial focus is particularly critical to identify in this step because it affects the risk evaluation and inventory provided to the board of directors and audit committee. Stated formally:

\section{$\mathrm{H} 1$ : Groups comprised of accountants will place greater significance on financial risk} factors than groups comprised of cross-functional managers.

Our second research question addresses whether this hypothesized financial focus extends to groups of individuals who have a financial, but non-accounting background. This is an important question because research indicates that a financial focus may not be the exclusive domain of accountants. Evidence from the balanced scorecard (BSC) literature provides support for the contention that a focus toward financial issues may persist because of the financial context, not simply because of the financial manager. In a field study of a major bank that adopted - and later abandoned - the BSC, Ittner, Larcker, \& Meyer (2003) found that general decision makers placed the most weight on quantitative financial measures. The authors ruled out the rational decision-maker hypothesis that the non-financial measures received less weight because they contained little incremental information. Rather, they concluded that psychological biases toward the financial measures provided a better explanation. Rich (2007) added to this evidence with a study of practicing managers, finding continued overreliance on financial measures. This bias contradicts the main objective behind the development of the BSC - to address the overweighting of quantitative, financial measures in performance evaluation, and balance their use with subjective, judgmental measures (Kaplan \& Norton, 1992). This research is consistent with other information processing literature indicating that cognitive biases play a role in the differential weights placed on equally informative performance evaluation measures (Lipe \& Salterio, 2000, 2002).

In our first experiment, we propose that while accounting groups may focus on financialrelated risks in an ERM task, cross-functional groups would not. Our second question aims to examine these groups more closely. If the arguments we formalize in $\mathrm{H} 1$ hold and cross-functional groups do not exhibit the bias, is it because the members are not accountants or because the members are cross-functional? We ask this to determine if it is sufficient for an organization to construct any group of managers (financial background or not) rather than accountants to complete the ERM task, or if the group must be constructed with cross-functional managers (training and work experience in non-financial areas). In other words, is the source of bias the accountants, or the lack of cross-functionality?

To address this issue, we extend our research to a setting with financially concentrated, but non-accounting, groups. We define financially concentrated groups as those whose members have a financial background, either through undergraduate training or through work experience. 
H2: Groups composed of financially concentrated managers will place greater significance on financial risk factors than groups composed of cross-functional managers.

\section{Method}

\section{Sample}

Participants were graduate students in either the MBA (Master of Business Administration) or MAC (Master of Accounting) program at two large public universities in the U.S. Total active participants included 75 MBA students, enrolled in a management accounting course and 69 MAC students, enrolled in an information technology risk and controls course. The participants were divided into groups of threemembers each. This mimics current practice, as most ERM teams involved in risk prioritization are very small, with no more than three or four members (Mehta, 2010). In total, we formed 25 MBA groups and 23 MAC groups. Most participants (83\%) reported having some work experience in a business field (experience may include internships). Table 1, Panel A includes demographic statistics overall for both experiments. Panel B includes MACs and Panel C includes MBAs: both for experiment one. Panel D reports demographic statistics for MBA participants in experiment two. For both experiments as a whole, average age was 27.35 (sd 5.73), and was significantly lower for MACs than for MBAs $(p<.0001)$. Our sample contained significantly more males $(61 \%)$ than females $(39 \%)$, however the majority of groups ( 41 of 48 ) were comprised of mixed members. There were no significant differences in undergraduate GPA $(p=.996)$ between MACs and MBAs. A qualitative analysis indicates that 70 percent $(n=48)$ of MACs have an undergraduate accounting degree, while no MBAs had an undergraduate accounting degree. Undergraduate finance degrees are held by 10 percent $(n=5)$ of MBAs in experiment one and 44 percent $(n=12)$ in experiment two. We surveyed group members on their knowledge of and prior experience with ERM. MAC students indicated that they had significantly more in-class experience with ERM tasks than did MBAs $(p<.0001)$, however, there was no significant difference between the groups with respect to workrelated ERM experience $(p=.224)$. None of the demographic variables were significant covariates in the analysis.

Table 1

Descriptive Statistics - All Active Participants

\begin{tabular}{|c|c|c|c|c|}
\hline Panel A: Total & $\mathrm{n}^{\mathrm{a}}$ & Mean & $\underline{\mathrm{sd}}$ & Range \\
\hline Age (years) & 143 & 27.35 & 5.73 & $21-56$ \\
\hline Undergrad GPA (0-4.0) & 138 & 3.49 & .34 & $2.1-4.0$ \\
\hline ERM Experience Student & 114 & 2.80 & .86 & $1-4^{\mathrm{a}}$ \\
\hline ERM Experience Work & 140 & 3.02 & .75 & $1-4^{\mathrm{a}}$ \\
\hline $\begin{array}{l}\text { Gender } \\
\text { a Scale: } 1=\text { Highly experien } \\
\text { have read about; } 4=\text { Never }\end{array}$ & $\begin{array}{l}61 \% \\
d ; 2= \\
\text { eard } t\end{array}$ & $\begin{array}{l}\text { en, } 39 \% \\
\text { e exper } \\
\text { erm bef }\end{array}$ & $\begin{array}{l}n \\
3=\mathrm{No}\end{array}$ & se, \\
\hline
\end{tabular}


Table 1 (continued)

Descriptive Statistics - All Active Participants

\begin{tabular}{|c|c|c|c|c|}
\hline Panel B: MAC & $\underline{n}^{d}$ & Mean & $\underline{s d}$ & Range \\
\hline Age (years) & 68 & 25.15 & 5.86 & $21-56$ \\
\hline Undergrad GPA (0-4.0) & 66 & 3.52 & .285 & $2.8-4.0$ \\
\hline ERM Experience Student & 66 & 2.29 & .82 & $1-4$ \\
\hline ERM Experience Work & 65 & 2.94 & .73 & $2-4$ \\
\hline Gender & \multicolumn{4}{|c|}{$49 \%$ men, $51 \%$ women } \\
\hline Panel C: MBA Exp. \#1 & $\mathrm{n}^{\mathrm{d}}$ & Mean & $\underline{s d}$ & Range \\
\hline Age (years) & $\overline{48}$ & 28.94 & 3.52 & $23-38$ \\
\hline Undergrad GPA (0-4.0) & 45 & 3.52 & .34 & $2.1-4.0$ \\
\hline ERM Experience Student & 48 & 3.23 & .63 & $2-4$ \\
\hline ERM Experience Work & 48 & 3.04 & .798 & $1-4$ \\
\hline Gender & \multicolumn{4}{|c|}{$66 \%$ men, $34 \%$ women } \\
\hline Panel D: MBA Exp. \#2 & $\underline{\mathrm{n}}$ & Mean & $\underline{\mathrm{sd}}$ & Range \\
\hline Age (years) & 27 & 30.07 & $6 . \overline{58}$ & $22-45$ \\
\hline Undergrad GPA (0-4.0) & 27 & 3.34 & .42 & $3.3-4.0$ \\
\hline ERM Experience Student & 27 & 3.30 & .61 & $2-4$ \\
\hline ERM Experience Work & 27 & 3.19 & .74 & $1-4$ \\
\hline Gender & \multicolumn{4}{|c|}{$81 \%$ men, $19 \%$ women } \\
\hline
\end{tabular}

${ }^{\mathrm{a}}$ These numbers do not equal 144 total participants, 69 MAC participants, and 49 MBA participants in Experiment 1 due to missing demographic information.

\section{Task and Procedures for Experiment One}

In theory, ERM appears to be a succinct and relatively simple model for compliance, governance, and growth in shareholder value (Power, 2009; Roberts 2005): identify risks across the organization and design risk response strategies that are explicitly linked to organizational objectives. In practice, as is the case with most managerial techniques, the devil is in the implementation. Although no cookie-cutter approach exists to implementing ERM, most programs include three broad activities: risk identification, risk prioritization, and strategic planning (Barton, Shenkir, \& Walker, 2001; Shaw, 2005). It is the approach to and choices made in implementing each of these three activities that will necessarily determine the effectiveness or ineffectiveness of the overall program.

Experiment one provides evidence on whether a homogenous group of accountants exhibits a focus on financial risk factors that is not found in a cross-functional group of managers, in the risk prioritization activity. For the MAC students, our proxy for accountants, the instructor randomly assigned participants to each group. For the MBA students, our proxy for cross-functional managers, the instructor assigned students to cross-functional groups based on their undergraduate degree, their MBA concentration 
area, or their current work title. The assignment was done to most closely match the student's background with the management role assumed in the group. Both sets of students had one hour in class, meeting face to face, to complete the task. Students received no compensation or class credit; however, their regular instructor was present and noted their attendance. Proctors instructed students to complete the group task, and then answer an individual questionnaire. Time to complete the task for all groups ranged from 25 minutes to 65 minutes, with a mean of 46.6 for the MBAs and a mean of 32.2 for the MACs. This difference is statistically significant, and is discussed further in the Results section.

The task required participants to play a role on the management team of a large, publicly traded food production company. For MAC groups, the background information described the participants' roles as accountants in the finance, accounting, and legal department of the company. Thus, all accountants had the same role. MBA group members were assigned the role of vice president of one of three functional areas sales and marketing; finance, accounting, and legal; or production and operations. Thus, each participant had a different role. To examine a potential effect of role assignment, we gathered pilot data in the same manner but without explicitly identifying the role as VP of a specific functional area, instead stating that the individual was simply a VP of the company. Results were not statistically different from those with specific role identification.

All groups in all treatments received the same set of risk factors in the same order. The materials stated two group objectives. One, groups were asked to rate every risk factor on a scale from $0-100$ based on significance to the organization overall. We excluded a portion of the MBA groups from the rating task in order to test for an effect of the rating task on the groups' risk inventory. Statistical testing reveals no significant difference in the mean responses or outcomes of the groups and therefore we collapsed the groups into one sample to increase power. The groups excluded from this task are also excluded from the analysis on the rating task, as shown in Table 2. Instructions noted that the rating task was not a relative ranking between risks, and that groups could assign the same significance to more than one risk. Two, groups were told to determine a rank-ordered master risk inventory for the organization's board of directors and audit committee. Groups were not explicitly told to use their ratings from objective one, although we observed some groups doing so. The complete materials included background information and memos describing the risks identified by managers in each of three departments. The background information contained three risks general to the company, departmental memos contained five risks specific to that functional department (corresponding to the functional roles noted above). Risks associated with operations include issues of product quality, natural disasters and power outages, and relations with suppliers. Sales and marketing risks include changing consumer preferences, loss of major customers, global competition, and brand damage due to recalls. Financial risks were comprised of interest rate changes, debt levels, litigation costs, and tax liability. Groups were explicitly allowed to generate and include risks not specifically identified in the accompanying information. Upon completion of the group task(s), participants individually completed a questionnaire that contained manipulation 
checks, gathered demographic data, and assessed members' perceptions of their group's communication, processes and outcomes.

\section{Task and Procedures for Experiment Two}

While experiment one tests differences between functionally homogeneous accountants and functionally diverse managers, experiment two examines whether financial bias is the domain of accountants, or whether financial bias extends to non-accountants (with financial backgrounds). We conduct these tests by comparing MAC groups to crossfunctional MBA groups in experiment one. Then, we compare cross-functional MBA groups to financially concentrated MBA groups in experiment two.

The case materials and procedures for experiment two were identical to those used for experiment one, with one exception. As before, we assigned students to groups based upon their undergraduate major or current work experience. Half of the groups were created with cross-functional members, with each member assigned the role of vice president of one of three functional areas - sales and marketing; finance, accounting, and legal; or production and operations (based on undergraduate major or work experience). To create financially concentrated groups, the remaining half of the groups comprised members who had financial concentrations in their undergraduate degrees or work experience. All three members of these groups were given information that described each participant's role as vice president in the finance, accounting, and legal department of the company. Thus, the financially concentrated MBA groups completed the experiment under the same conditions as the MAC groups in experiment one. Time to complete the task for all groups ranged from 25 minutes to 60 minutes, with a mean of 48.0 minutes for the cross-functional MBAs and a mean of 37.5 minutes for the financially concentrated MBAs. This difference is significant at $p=0.079$, and is discussed further in the Results section.

We developed the background and departmental risks from the risk factor disclosure section (Item 1a) of Tyson Foods' 2007 10-K annual report. The balanced scorecard provided a framework for categorizing Tyson's risk factors into departmental areas. Kaplan and Norton's $(1992,1996)$ BSC reflects four perspectives of corporate performance: learning and growth, customer, business process, and financial. Using research that links the BSC to ERM (Beasely, Chen, Nunez, \& Wright, 2006; Calandro \& Lane 2006; Woods 2007), we classified the risk factors identified in Tyson's 10-K into three of these categories, customer, business process, and financial. The customer perspective focuses on risks related to customers, markets, and reputation; business processes include threats to supply chains, raw materials procurement, production interruptions, and internal operation processes; and financial risks involve interest rate and credit risks, volatility in capital markets, debt financing, and tax issues (Beasely, Chen, Nunez, \& Wright, 2006; Calandro \& Lane 2006; Woods 2007). The final materials contained five risk factors in each of these three categories, and three general background risks (common risks) related to overall company issues. In keeping with the types of risk factors listed by Tyson, we did not include risk factors related to learning and growth. Figure 1 shows a timeline of the procedures for both experiments. 


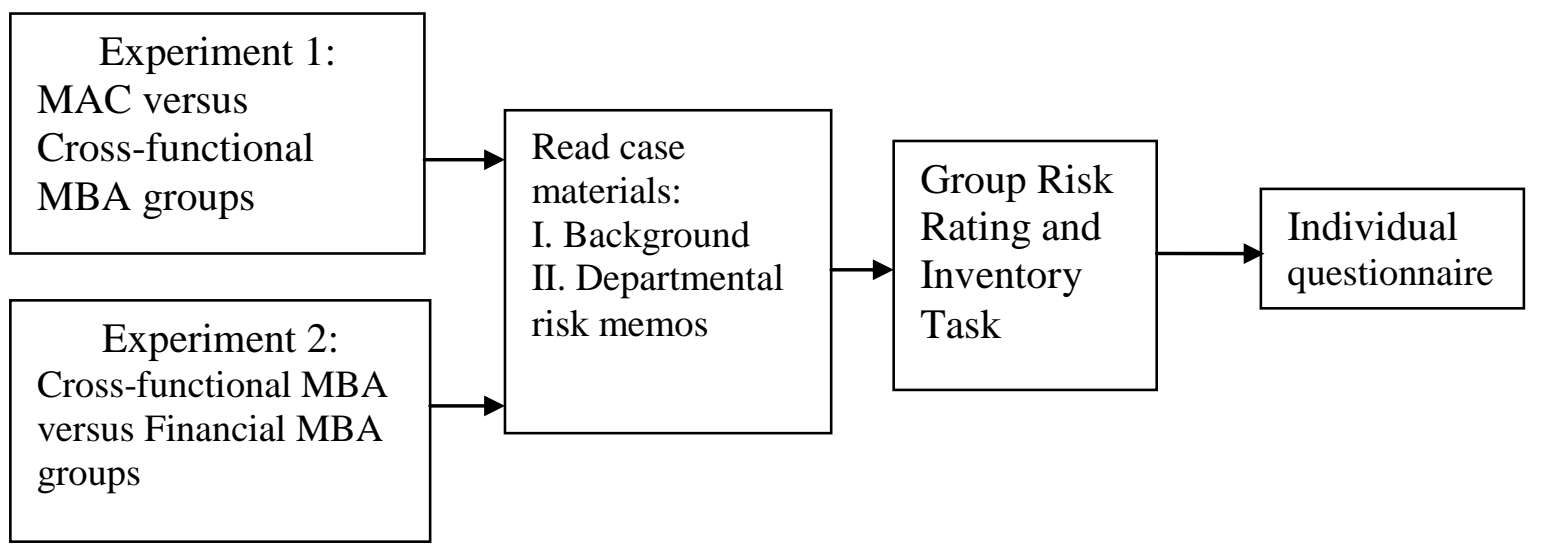

Figure 1. Overview of procedures

\section{Dependent Variables}

We calculate two dependent variables to test our hypotheses on financial focus. The first is an average of the groups' ratings of the significance of the financial risks to the company. The theoretical range for this variable is $0-100$; the actual observed range for the full sample including both experiments was 35-88, with a mean (sd) of 63.32 (14.48). The second dependent variable is a weighted measure, created by assigning points to each financial factor included in the top eight factors generated by each group and listed in their risk inventory. We assigned eight points if the financial risk factor was listed first, seven points if it was second, and so on, down to one point if the financial risk factor was listed in the eighth position. We limit our analysis to the top eight risk factors, as this was the most factors listed by five of the groups. The theoretical range for this variable is $0-30$ ( 5 factors maximum); the actual observed range for the full sample including both experiments was 1-25, with a mean (sd) of 12.59 (2.47). Tables 2 and 3 include statistics for the dependent variables, by treatment group.

\section{Results}

\section{Experiment One}

Experiment one tests whether homogeneous MAC groups will produce risk ratings and final risk inventories focused toward financial risks, compared with cross-functional MBA (CFMBA) groups. As presented in Table 2, Panel A, the MAC groups' mean rating of the financial risk factors was 67.24, while the CFMBAs was 55.50. This difference is significant $(\mathrm{F}=4.74 ; \mathrm{p}=0.038)$, providing support for $\mathrm{H} 1$. Next, we compared the weighted financial risk variable means from the MAC and CFMBA groups. Table 3 , Panel A presents these results. When compared with CFMBA group solutions, MAC group solutions resulted in a significantly higher weighted financial risk variable, mean (sd) of $13.83(3.28)$ to $10.81(4.97)$. This difference is significant at $p=0.028$. Our analysis on both dependent variables supports Hypothesis 1, suggesting that homogenous groups of accountants exhibit a focus toward financial-related risk factors in both 
significance rating and inclusion on the risk inventory, compared to cross-functional groups.

\section{Experiment Two}

Our primary objective for experiment two is to examine whether financially concentrated groups (other than MACs) exhibit the financial focus. We conducted a second experiment with groups of cross-functional MBAs and groups of financially concentrated MBAs. Results presented in Panel B of both Tables 2 and 3 refute the expectation that generalist training and experience dissuades financially concentrated MBAs from focusing on financial-related risks. The mean significance rating of the financial risk factors was 48.12 for cross-functional MBAs versus 75.45 for financially concentrated MBAs (Table 2, Panel B). This difference is significant at $p=0.003$. Table 3, Panel B presents the statistical analysis of the weighted financial risk variable. We find a significant difference $(p=0.024)$ in the mean responses of cross-functional MBAs (10.6) compared to financially concentrated MBAs (19.5). Thus, we find evidence to support Hypothesis 2 and conclude that financially concentrated MBAs demonstrate financial focus when compared to cross-functional MBAs.

\section{Combined data}

The results on experiments one and two suggest that groups comprised of members with financial backgrounds, both accountants and non-accountants, appear to exhibit a focus toward the financial-related risk factors during risk prioritization of an ERM process. We conducted a supplementary analysis on the combined data of experiments one and two, collapsing the MAC and financially concentrated MBAs into one sample and the cross-functional MBAs from both experiments into one sample. Panel $\mathrm{C}$ of both Tables 2 and 3 show a significant difference between the groups on both dependent variables. The mean rating of financial risk factors by all financial groups was 68.45 , significantly higher $(p=0.001)$ than cross-functional groups' mean ratings $(52.66)$. The weighted financial risk variable (ranking) is significantly higher (mean 14.67) than the combined CFMBAs (mean 10.76) at $p=0.003$. These results corroborate our hypotheses, that homogeneous, financially oriented groups focus on financial-related risk factors, when compared to cross-functional groups.

Table 2

ANOVA results for tests of $\mathrm{H} 1$ : Financial Bias

$D V=$ Avg. Rating of Financial Risks, $0=$ least to $100=$ most significant

Panel A: Experiment 1

\begin{tabular}{|c|c|c|c|c|c|}
\hline Group & $\begin{array}{l}\text { Financial } \\
\text { MAC }\end{array}$ & $\frac{n}{23}$ & $\frac{\text { Mean }}{67.24}$ & $\frac{\underline{s d}}{13.23}$ & $\frac{\text { Range }}{41-88}$ \\
\hline Composition & $\begin{array}{l}\text { Cross-functional } \\
\text { MBA }\end{array}$ & 8 & 55.50 & 12.83 & $37-75$ \\
\hline
\end{tabular}


Table 2 (continued)

ANOVA results for tests of $\mathrm{H} 1$ : Financial Bias

$D V=$ Avg. Rating of Financial Risks, $0=$ least to $100=$ most significant

Panel B: Experiment 2

\begin{tabular}{|c|c|c|c|c|c|}
\hline Group & $\begin{array}{l}\text { Financial } \\
\text { MBA }\end{array}$ & $\frac{n}{4}$ & $\frac{\text { Mean }}{75.45}$ & $\frac{s d}{8.32}$ & $\frac{\text { Range }}{69-87}$ \\
\hline Composition & $\begin{array}{l}\text { Cross-functional } \\
\text { MBA }\end{array}$ & 5 & 48.12 & 9.74 & $35-60$ \\
\hline
\end{tabular}

Panel C: Combined Data

\begin{tabular}{|c|c|c|c|c|c|}
\hline & Financial & $\frac{\mathrm{n}}{27}$ & $\frac{\text { Mean }}{68.45}$ & 12.84 & $\frac{\text { Range }}{41-88}$ \\
\hline Group & MIBA and MAC & & & & \\
\hline \multirow[t]{2}{*}{ Composition } & $\begin{array}{l}\text { Cross-functional } \\
\text { MBA }\end{array}$ & 13 & 52.66 & 11.90 & $35-75$ \\
\hline & Total & 40 & 63.32 & 14.48 & $35-88$ \\
\hline
\end{tabular}

Source of Variation

df $\quad$ F Statistic $\quad$ p-value

Panel A: Experiment 1

$M B A$ versus $M A C$

$\left(R^{2}=14.0 \%\right)$

$\begin{array}{lll}1 & 4.74 \quad .038\end{array}$

Panel B: Experiment 2

Financial versus Cross-functional (all

MBA)

$\left(R^{2}=73.9 \%\right)$

$1 \quad 19.80 \quad .003$

Panel C: Combined Data

Cross-functional (MBA) versus Financial

(MAC and MBA)

$1 \quad 13.88$

.001

$\left(R^{2}=26.8 \%\right)$

Table 3

ANOVA results for tests of $\mathrm{H} 1$ : Financial Bias

$\mathrm{DV}=$ Weighted Financial Risk, $0=$ no financial factors listed in top eight of risk list to 30

$=$ all five financial risk factors listed as top five of risk list

Panel A: Experiment 1

\begin{tabular}{llllll}
\hline & Financial & $\frac{\mathrm{n}}{23}$ & $\frac{\text { Mean }}{13.83}$ & $\frac{\mathrm{sd}}{3.28}$ & $\frac{\text { Range }}{8-21}$ \\
Group & MAC & & & & \\
Composition & $\begin{array}{l}\text { Cross- } \\
\text { functional } \\
\text { MBA }\end{array}$ & 16 & 10.81 & 4.97 & $1-21$ \\
& MBA & & & & \\
\hline
\end{tabular}


Table 3 (continued)

ANOVA results for tests of $\mathrm{H} 1$ : Financial Bias

$\mathrm{DV}=$ Weighted Financial Risk, $0=$ no financial factors listed in top eight of risk list to 30

$=$ all five financial risk factors listed as top five of risk list

Panel B: Experiment 2

\begin{tabular}{|c|c|c|c|c|c|}
\hline & & $\underline{\mathrm{n}}$ & Mean & $\underline{s d}$ & Range \\
\hline Group & $\begin{array}{l}\text { Financial } \\
\text { MBA }\end{array}$ & 4 & 19.5 & & $17-25$ \\
\hline Composition & $\begin{array}{l}\text { Cross-functional } \\
\text { MBA }\end{array}$ & 5 & 10.6 & 5.18 & $2-15$ \\
\hline
\end{tabular}

Panel C: Combined Data

\begin{tabular}{llllll}
\hline & Financial & $\frac{\mathrm{n}}{27}$ & $\frac{\text { Mean }}{14.67}$ & $\frac{\mathrm{sd}}{3.86}$ & $\frac{\text { Range }}{8-25}$ \\
Group & MBA and MAC & & & & \\
Composition & Cross-functional & 21 & 10.76 & 4.89 & $1-21$ \\
& MBA & 48 & 12.59 & 2.47 & $1-25$ \\
\hline & Total & 48 & & & \\
\hline
\end{tabular}

Source of Variation

Panel A: Experiment 1

MBA versus MAC

$\left(R^{2}=12.36 \%\right)$

Panel B: Experiment 2

Financial versus Cross- functional (all

MBA)

$\left(R^{2}=54.3 \%\right)$

Panel C: Combined Data

Cross-functional (MBA) versus Financial

(MAC and MBA)

$\left(R^{2}=17.2 \%\right)$ df $\quad$ Statistic p-value

$\begin{array}{lll}1 & 5.22 & .028\end{array}$

1

8.31

.024

$1 \quad 9.57$

.003

\section{$\underline{\text { Time to Complete }}$}

Although we did not formalize expectations regarding the time to complete the task, our descriptive statistics reveal differences between the treatment groups. It appears that groups with homogeneous functional compositions spent less time on task than groups with cross-functional compositions. In experiment one, MAC groups spent significantly less time on task than CFMBA groups (32.2 min to 46.6 min, respectively; $p=.0001$ ). Similarly, FMBA groups spent less time than CFMBA groups in experiment two, although this difference is not significant at a $p=0.05$ level ( $37.5 \mathrm{~min}$ to $48.0 \mathrm{~min}$, respectively; $p=0.079$ ). Combining the data of the two experiments shows that financially concentrated groups spend 33.0 minutes while cross-functional groups spent 
46.7 min. This difference is significant at $p<0.0001$. A likely explanation is that the diversity of backgrounds and knowledge present in a cross-functional group encourage greater discussion and negotiation, and that a common focus amongst group members results in less time to complete the task and come to a consensus. Prior group research in marketing and product development suggests that participative decision-making and conflict resolution in functionally diverse groups are more time-consuming and less efficient than in homogenous groups (for a review, see Troy, Hirunyawipada, \& Paswan 2008). The marketing research also indicates that employee satisfaction can suffer because of increased time required to work in cross-functional groups. Despite this, cross-functionality is largely considered to be advantageous to the overall outcome precisely because of the diversity of backgrounds and knowledge. Organizations may wish to actively manage the likelihood that cross-functional groups will require greater time commitments.

\section{Conclusion}

Litigation, regulation, globalization, and technological advances are just a few of the forces that contribute to an increasingly uncertain and risky environment: one that influences an organization's ability to achieve its objectives. Enterprise risk management promises a structured approach for managers who want to identify the risks created by these and other forces in order to strategize solutions. However, if we have learned anything in the wake of the financial crisis of 2008, it is that risk 'management' may be the latest management breakthrough that fails to live up to its promise. Since ERM began its steady climb in popularity in the mid-1990s, textbooks have been written, C-suite level positions have been created, frameworks have been disseminated, and journals have been renamed to cater to the risk management wave. Such was the attention on ERM that Power (2004) proclaimed that we had entered the age of 'the risk management of everything'. The danger of this expansive view is that by managing everything, we may have in fact truly managed nothing (Power, 2009). Recent corporate and government behavior seems to support this dismal proposition (e.g., the aforementioned financial crisis, Toyota's recall debacle, and the British Petroleum Deepwater Horizon disaster). Given the relative dearth of academic research on ERM (Mikes, 2009), it is not clear whether these events indicate a failure of the philosophy, the implementation, or some other factor outside the scope of ERM. Our objective in this paper is to explore how a common implementation choice, singular reliance on accounting personnel at a crucial point in the process, may bias the outcome of a risk management task. We hope to show the impact of such choices and thus encourage additional research into whether and how ERM can live up to its promise.

We report the results of two experiments designed to investigate the effects of functional composition on the outcomes of one step in the risk management process. Results from both experiments show that functionally homogeneous groups, whether all accountants or other financially oriented managers: 1) rate financial-related risks as more important, and 2) include more financial-related risks and rank them higher on organizational risk inventory lists than do functionally diverse groups. In practice, this 
financial focus may alter the allocation of resources and attention paid to non-financial risks. We also found that groups with a shared background spend less time completing the ERM rating and ranking task than groups comprising members with diverse backgrounds.

Taken together, the findings of this study suggest that the functional composition of an ERM group has significant effects on the outcome, including both the evaluation of each risk and the composition of the final risk inventory. These results are noteworthy as the risk inventory list makes up the information set from which the board and audit committee make decisions, and therefore, necessarily affects the corporate governance function of the organization. This finding is important because ERM proponents insist that successful practices be cross-functional, yet ERM responsibilities are often housed in accounting-type functions. We acknowledge that any employee group would likely be subject to departmental biases: sales representatives will focus on sales risks, while operational representatives will focus on operational risks. However, given that accounting and finance functions appear to hold heavy responsibility for ERM, it is imperative that we understand how this reality affects risk management.

It is also important to note that MBAs are trained to be broad thinkers and business generalists, not specialists (Kachra \& Schnietz, 2008). Employers value MBAs for their ability to transcend functional disciplines and make decisions with a holistic view of the organization (Gupta \& Smith, 2007). MBAs are also likely to have training in crossfunctional group work as an increasing number of universities have reengineered their MBA programs to meet the demands of prospective employers (DeMoranville, Aurand, \& Gordon, 2000). The resulting MBA core curriculum promotes cooperation among classmates and generalized management training. Yet, MBAs with a financial background exhibited a bias toward financial risks. This should give businesses pause when assuming that a generalist graduate degree ensures a generalist, organizational focus.

\section{$\underline{\text { Limitations }}$}

Our study is subject to the common limitations of experimental research. First, because cases necessarily abstract from actual business practices, it is not possible to simulate the rich context of a business setting. However, we developed our case from actual company disclosures to ensure realism and assigned management roles based upon the participants' undergraduate major or work experience. Second, the participants had limited time to complete the task. While most business practices would not be subject to an artificial time limit, it is realistic to assume that practicing managers operate under their own time constraints. An ERM initiative is not among most managers' primary responsibilities, and therefore, it is quite likely that time constraints exert some influence in the real world. Third, our sample sizes may limit the generalizability of our findings, and an extension of this research with more participant groups is warranted. However, their relatively small size likely biases against us finding the differences we report. Finally, and most notably, although the MBA students have significant work experience, 
graduate students have different incentives than practicing managers. A field study or multiple case studies with managers offer exciting opportunities for future research.

We cannot answer the question of whether the role of accounting in ERM is good or bad, right or wrong. Power (2009) offers the conjecture that ERM has failed, and that this failure is partly because risk management became lost in the procedural detail of internal control, financial regulations, and accounting systems. Others argue that accountants have valuable expertise and experience in traditional risk management and regulatory compliance, and that recent risk management failures are more the result of skewed incentives and personal greed (Barton, Shenkir, \& Walker, 2009). We also recognize a view that financial risks may simply be the most important risks to an organization, and that the accountants get it right. Our design does not allow such conclusions, and we make no claim about the normative outcome of ERM risk inventories. The very nature of risks is that they are uncertain, thus we cannot claim that one answer is better than another is. This paper merely demonstrates that a bias exists and that it influences an outcome. Nonetheless, this study does provide an exploratory look into ERM practices and provides an initial baseline that future research can build upon. For example, longitudinal group studies can examine risk management practices at various stages of group development. Another route of exploration is to study the effect of various incentives on groups and individuals.

Much more work is needed before the verdict is in on ERM. Recent surveys show that the implementation and understanding of ERM is far behind expectations (Protiviti, 2010). Thus, there is room for improvement. By being mindful about the definition of risk appetite, the impact of individual proclivities, and the limits of risk management, ERM may yet live up to its promise. In sum, the obituary is premature.

\section{References}

Barton, T. L., Shenkir, W. G., \& Walker, P. L. (2001). Managing risk: An enterprise-wide approach. Financial Executive, 17(2), 48-52.

Barton, T. L., Shenkir, W. G., \& Walker, P. L. (2002). Making Enterprise Risk Management Pay Off. Upper Saddle River, NJ: Prentice Hall PTR.

Barton, T. L., Shenkir, W. G., \& Walker, P. L. (2009). ERM: The evolution of a balancing act. Financial Executive, 25(5), 30-33.

Barton, T. L., Shenkir, W. G., \& Walker, P. L. (2010). ERM after the financial crisis. Financial Executive, 26(3), 18-22.

Beasely, M. S., Banson, B. C., \& Hancock, B. V. (2008). Rising Expectations. Journal of Accountancy, 205(4), 44-51.

Beasely, M. S., Chen, A., Nunez, K., \& Wright, L. (2006). Working hand in hand: Balanced scorecards and enterprise risk management. Strategic Finance, 87(9) 49-56.

Beasely, M. S., Clune, R., \& Hermanson, D. R. (2005). Enterprise risk management: An empirical analysis of factors associated with the extent of implementation. Journal of Accounting and Public Policy, 24, 521-531. 
Beasely, M. S., \& Frigo, M. L. (2007). Strategic risk management: Creating and protecting value. Strategic Finance, 88(11), 25-31, 53.

Birnberg, J. G., \& Shields, M. D. (1984). The role of attention and memory in accounting decisions. Accounting, Organizations, and Society, 9(3/4), 365-382.

Calandro, J., \& Lane, S. (2006). Insights from the balanced scorecard: An introduction from the enterprise risk scorecard. Measuring Business Excellence, 10(3), 31-40.

COSO. Committee of Sponsoring Organizations. (2004). Enterprise Risk Management Integrated Framework. New York: COSO.

DeMoranville, C., Aurand, T., \& Gordon, G. (2000). The delivery of an undergraduate, cross-functional business principles program: One university's continuing journey. Marketing Education Review, 10(3I), 29-41.

Fraser, J. R., \& Simkins, B. J. (2007). Ten common misconceptions about enterprise risk management. Journal of Applied Corporate Finance, 19(4), 41-47.

Gupta, P., \& Smith, J. (2007). Traditional Master of Business Administration versus the MBA with specialization. Journal of Education for Business, 82(6), 307-312.

Hambrick, D., Cho, T., \& Chen, M. J. (1996). The influence of top management team heterogeneity on firms' competitive moves. Administrative Science Quarterly, 41, 659-684.

Hoffman, L. R, \& Maier, N. M. (1961). Quality and acceptance of problem solutions by members of homogenous and heterogenous groups. Journal of Abnormal and Social Psychology, 62(2), 401-407.

Ittner, C. D., Larcker, D. F., \& Meyer, M. W. (2003). Subjectivity and the weighting of performance measures: Evidence from a balanced scorecard. The Accounting Review, 78(3), 725-758.

Kachra, A., \& Schnietz, K. (2008). The capstone strategy course: What might real integration look like? Journal of Management Education, 32(4), 476-508.

Kaplan, R. S., \& Norton, D. P. (1992). The balanced scorecard: Measures that drive performance. Harvard Business Review, January-February, 1-8.

Kaplan, R. S., \& Norton, D. P. (1996). The balanced scorecard: Translating strategy into action. Boston, MA: Harvard Business School Press.

Lipe, M. G., \& Salterio, S. (2000). The balanced scorecard: Judgmental effects of common and unique performance measures. The Accounting Review, 75(3), 283-298.

Lipe, M. G., \& Salterio, S. (2002). A note on the judgmental effects of the balanced scorecard's information organization. Accounting, Organizations, and Society, 27(6), 531-540.

March, J., \& Shapira, Z. (1987). Managerial perspectives on risk and risk taking. Management Science, 33(11), 1404-1418.

Martin, D., \& Power, M. (2007). The end of enterprise risk management. AEI-Brookings Joint Center for Regulatory Studies. Washington, DC: Brookings Institute.

Mayo, D., \& Hollander, D. (1991). Acceptable evidence: Science and values in risk management. Oxford: Oxford University Press.

Mehta, S. 2010. Enterprise risk management: Insights and operationalization. Financial Executives Research Foundation, Executive Report. Morristown, NJ. 
Melone, N. P. 1994. Reasoning in the executive suite: The influence of role/experiencebased expertise on decision processes of corporate executives. Organization Science, 5(3), 438-455.

Mendoza, C., \& Bescos, P. L. (2001). An explanatory model of managers' information needs: Implications for management accounting. The European Accounting Review, 10(2), 257-289.

Mikes, A. (2009). Risk management and calculative cultures. Management Accounting Research, 20(1), 18-40.

Power, M. (2004). The risk management of everything. The Journal of Risk Finance, $5(3), 57-64$.

Power, M. (2009). The risk management of nothing. Accounting, Organizations, and Society, 34(6/7), 849-855.

Protiviti. (2010). Board risk oversight: A progress report. The Committee of Sponsoring Organizations of the Treadway Commission. Retrieved from http://www.coso.org/documents/Board-Risk-Oversight-Survey-COSOProviti_000.pdf

Rich, V. (2007).Interpreting the balanced scorecard: An investigation into performance analysis and bias. Measuring Business Excellence, 11(1), 4-11.

Roberts, H. (2005). Enterprise risk management: a long-term solution for compliance, governance and sustained growth in shareholder value. Retrieved from www.entropy-international.com

Shaw, J. (2005). Managing all of your enterprise's risks. Risk Management, 52(9), 2228.

Shenkir, W. G, \& Walker, P. L. (2006). Enterprise risk management and the strategyrisk-focused organizations. Cost Management, 20(3), 32-38.

Troy, L., Hirunyawipada, T., \& Paswan, A. (2008, November). Cross-functional integration and new product success: An empirical investigation of the findings. Journal of Marketing, 72, 132-146.

Walker, P. L., Shenkir, W. G., \& Barton, T. L. (2003). ERM in practice. Internal Auditor, 60(4), 51-55.

Woods, M. (2007). Linking risk management to strategic controls: A case study of Tesco plc. International Journal of Risk Assessment and Management, 7(8), 1074-1088. 